\title{
Effect of Matrix Rhythm Therapy on Chronic Vein Dysfunction Deep Foot Ulcer: A Case Report
}

\author{
Ketan Bhatikar* \\ Musculoskeletal \& Orthopaedics, Physiotherapist, St Marys \& Almeida, India
}

Submission: October 10, 2018; Published: November 26, 2018

*Corresponding author: Ketan Bhatikar, Musculoskeletal \& Orthopaedics, Physiotherapist, St Marys \& Almeida, Goa, India

\begin{abstract}
There are many different noninvasive physical modalities in physiotherapy that are used in the treatment of wound ulcer. Foot ulcers are more difficult to treat in any patient. It is more difficult if the patient having any peripheral neuropathy and/or circulatory problems. In previous studies ultrasound, LASER and interferential current are proved to be beneficial in treating some foot. The present study addressed 2 deep vein ulcer of a 48 years old male at Dr. Ketan Bhatikar's Sports Physiotherapy and Aqua Rehabilitation Center. To our knowledge, very fewer studies have focused on the effect of matrix rhythm therapy on wound/ ulcer. Therefore, in the present study, we evaluated the effect of matrix rhythm therapy along with the contemporary physiotherapy treatment (LASER + PEMF + Exercise). The study showed positive results in treating the deep vein ulcers. The present study concludes that Matrix Rhythm Therapy along with the Pulsed electromagnetic field therapy and LASER therapy is beneficial in the healing of a long-standing non-healing deep vein ulcer.
\end{abstract}

Keywords: Matrix Rhythm Therapy, Chronic Vein Dysfunction, Deep Foot Ulcer, Physiotherapy, Peripheral neuropathy, LASER therapy, Lowintensity laser therapy

Abbreviations: LILT: Low-Intensity Laser Therapy; PEMF: Pulsed Electromagnetic Field; DFS: Diabetic Foot Ulcer Scale

\section{Introduction}

A deep foot ulcer is an open sore on the foot that extends from superficial skin to the full thickness of the skin and may involve tendons, bones and other deep structures [1]. It is more likely seen in people with poor circulation and hence difficult to heal. The majority $(60-80 \%)$ of foot ulcers heal, while $10-15 \%$ of them will remain active, and $5-24 \%$ of them will finally lead to limb amputations [2]. If the ulcer is not treated in the right way then there are more chances of infecting this ulcer and leading to an abscess, cellulitis, gangrene or bone infections like osteomyelitis. Foot ulcers are difficult to treat in any patient and it is more difficult having any peripheral neuropathy, circulatory problems, abnormality of bones or muscles, atherosclerosis, Raynaud's phenomenon etc. If it not treated on time it may further lead to amputation [3]. Neuropathic wounds heal over a period of 20 weeks, while neuroischemic ulcers take longer duration and will more often lead to limb amputation [4]. The prevention of diabetic foot is crucial, considering the negative impact on a patient's quality of life and the associated economic burden on the healthcare system [5].

There are many different physical modalities used in the treatments of wound ulcer like Electrical stimulation therapy, Variety of foot protective devices (water filled and tied gloves), high voltage, pulse galvanic electrical stimulation, thermotherapy, laser, magnetotherapy, transcutaneous oxygen partial pressure, ultrasound, extracorporeal shockwave therapy, whole body vibration, and electrotherapy [6-9].
Pulsed Electromagnetic Field Therapy (PEMF) is a noninvasive, painless treatment for various injuries, bone-related conditions, depression and pains. A solenoid place in the machine works by emitting a pulsating, varying intensity and frequency electromagnetic field around the patient. Many research findings have shown a positive effect in wound healing [10]. A study in 1998 monitored in vitro by using human umbilical vein and bovine aortic endothelial cells, the effects of pulsed electromagnetic fields on the repopulation rate of denuded regions of endothelial cell monolayers and on endothelial cell reorganization into complex vessel-like structures. A small (20$40 \%$ ) but a statistically significant enhancement in the growth rate of denuded endothelial cell monolayers was observed in the presence of pulsed electromagnetic fields. The study cited discrete stages of neovascularization which were observed in the presence of the field that was qualitatively similar to stages of angiogenesis that observed in vivo [11].

Low-level laser therapy (spectral range 630-1000nm) is the most commonly used treatment modalities for any condition conditions that require stimulation of healing, relief of pain and inflammation, and restoration of function [12]. The laser is known to supply direct biostimulative light energy to body cells. The absorbed laser energy stimulates molecules and atoms of cells but does not cause the rapid or significant increase in tissue temperature [13]. Different laser wavelengths have different 
depths of penetration into human tissue as the Red laser has a deeper penetration depth than violet, blue, green, or yellow. Infrared and near-infrared light is not visible, but it has been demonstrated that laser penetrates human tissue deeper than visible red light [14].

Matrix Rhythm Therapy, developed by Dr. Ulrich G. Randoll is an important innovation in the effective treatment and prevention of a wide variety of medical conditions, especially in microcirculation and those including illnesses of the nervous and musculoskeletal system [15].

To our knowledge, very fewer studies till now have focused on the effect of matrix rhythm therapy on wound/ ulcer. Therefore, in the present study, we evaluated the effect of matrix rhythm therapy along with the contemporary physiotherapy treatment (LASSER + PEMF + Exercise) (Figure 1)
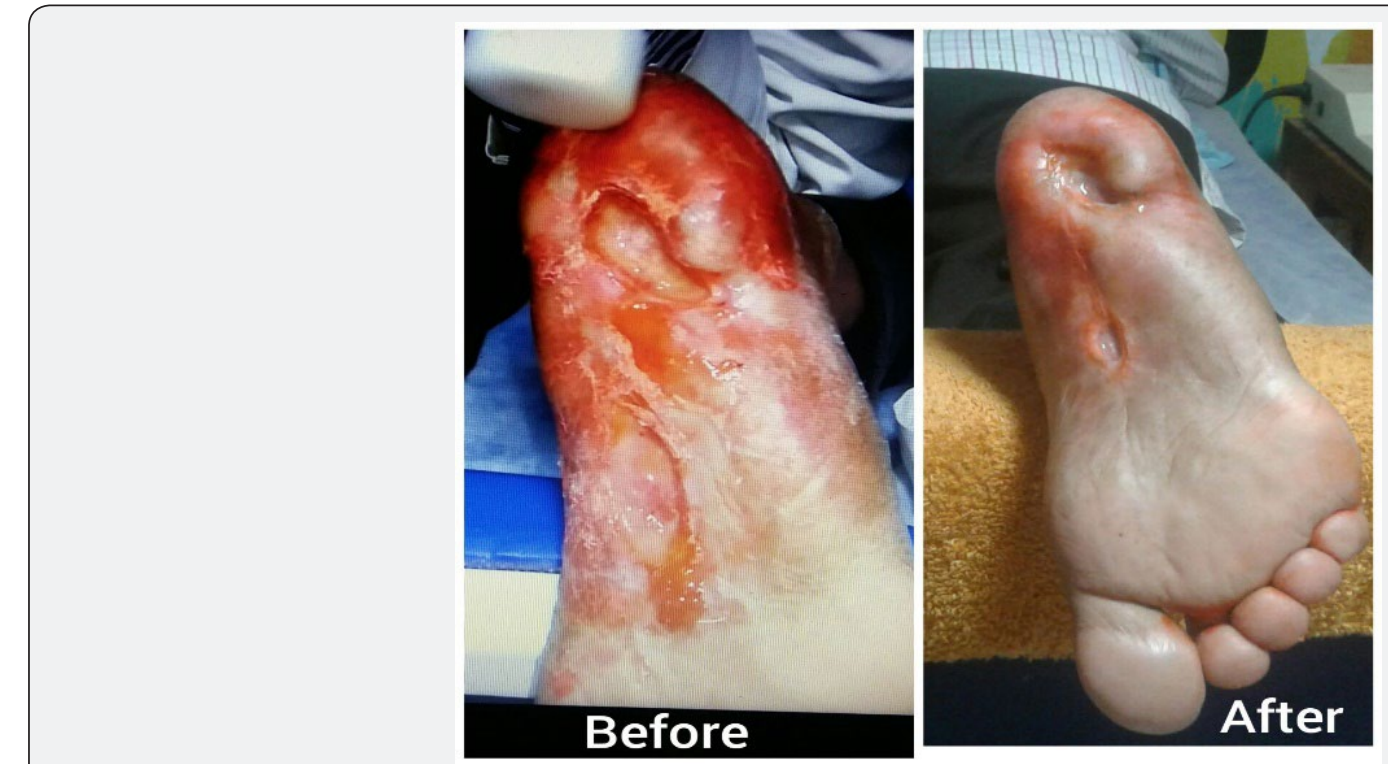

Figure 1: Deep vein ulcers at session 1 and session 25 treated with matrix rhythm therapy.

\section{Case Report}

A case of 48 years old male was presented with two wound ulcers ranging $3.8 \times 2 \times 2 \mathrm{~cm}$ and $2.4 \times 2.1 \times 1.8 \mathrm{~cm}$ width $\mathrm{x}$ breath $\mathrm{x}$ depth respectively. The patient was having no history of diabetes or hypertension. Patient reports confirmed that the patient was having an arterial block in the right femoral artery 3 years back. After the operation patient started experiencing a gradual increase in right lower limb muscle weakness and pain. The patient also developed knee stiffness in the right knee joint as the patient was adapted to heel raise high stoppage gait to avoid heel pain. The patient then developed the ulcer which was nonfoul smelling and non-healing in nature. The patient consulted varies medical treatment but found no relief. This had a significant financial impact on patients' quality of life. The patient so consulted to physiotherapy option at Dr. Ketan Bhatikar's Sports Physiotherapy and Aqua Rehabilitation Center.

As the patient was recruited to the study he was advised not to go for any other medical interventions. Patients inform consent was signed and treatment session was started. In the present study patient was treated with matrix rhythm therapy for 45 minutes on regular sessions continued for 20 days and alternate sessions for 20 sessions. Matrix rhythm therapy was given by a single therapist in medium frequency on the sole of the foot directed towards the edges of the wound ulcer and to the calf muscle in the prone position. The patient was treated for pain by pulsed electromagnetic field (PEMF) therapy for all the sessions.
The laser was given for 20 minutes on the open wound for all the sessions. Pre and post wound healing data and heel pain were recorded by the diabetic foot ulcer scale (DFS) questionnaire. DFS is a specific instrument designed to assess the impact of foot ulcers and their treatment on quality of life in people with diabetes [16,17].

\section{Discussion}

Recent studies have proved numerous physical modalities used in the treatment of ulcer in physical therapy. Soft tissue techniques, ultraviolet rays, ultrasound, ionozone therapy, electrical stimulation, radiant heat, pulsed electromagnetic field therapy, hydrotherapy etc. But even after many types of research in multidisciplinary care systems for ulcers, treatment is still difficult and treatment results are often unsatisfactory [18].

In the present study, pulsed electromagnetic field (PEMF) therapy along with LASER showed beneficiary effects in healing a chroniclong-standing foot ulcer. PEMF results in promoting healing by potentially increasing collagen synthesis, angiogenesis, and bacteriostasis. Similarly, a study was done to examine the effects of pulsed electromagnetic field (PEMF) therapy for promoting the healing and microcirculation of chronic diabetic foot ulcers. This study had 7 subjects in the PEMF group and 6 subjects in the control group. Study assessment on wound closure wound depth, and microcirculation was performed at the baseline, end of the treatment period, and 1-month follow-up. The PEMF group 
demonstrated an 18\% decrease in wound size, $28 \%$ increase in cutaneous capillary blood velocity and $14 \%$ increase in capillary diameter. In conclusion, PEMF therapy seemed to accelerate wound healing and improve microcirculation [19]. A study was done to assess the efficacy of low-intensity laser therapy (LILT) on the wound healing. 130 subjects were enrolled for the study and after randomization, the subjects were allocated to control and experimental groups each consisting of 65 subjects. 3 weeks of the study included laser therapy for group A and dressing for the control group. The study concluded that LILT has better healing of pressure ulcers when compared to the conventional wound management [20].

A study done to examine and compare the effect of massage and matrix rhythm therapy in young women on the peripheral blood circulation applied MRT to the left lower extremity for a single 30-minute session. The study concluded that after matrix rhythm therapy and massage application, blood velocity, artery diameter, and blood flow in arteries increased than did massage. The average increases in the blood flow rates in the popliteal and the posterior tibial arteries were $25.29 \% \pm 16.55 \%$ and $34.33 \% \pm 15.66 \%$, respectively. This suggests that matrix Rhythm Therapy can help in better blood circulation at any kind of wound [21]. The above explanation holds good for the healing of the wound in the present study, as may be due to the batter and increased blood circulation around the ulcer wound at the 38th sessions the mid-foot ulcer was almost healed and the heel ulcer was $1.8 \mathrm{x} 0.5 \mathrm{x} 0.5 \mathrm{~cm}$ width $\mathrm{x}$ breath $\mathrm{x}$ depth, Matrix-RhythmTherapy has a lasting effect on the cell matrix as well as on the extracellular matrix when applied from the exterior. It creates mechanical and magnetic vibrations according to the body's own characteristic micro-vibrations. It also does stimulation of the physiological and neuron receptors. Thus, it can indeed help to optimize the healing processhtt [22]. Another study stated a significant increase in the range of motion and sensory function at pre-treatment according to post-treatment $(p<0.01)$ after the application of MRT in Subjects with burns [23].

\section{Conclusion}

In the present study, we evaluated the effect of Matrix Rhythm Therapy along with the Pulsed electromagnetic field therapy and LASER therapy that found to be beneficial in the healing of a longstanding nonhealing wound ulcer. As this was a case report a detailed research with more number of subjects should be carried out to see the cost effect and effect of the physical modalities on the Wound or non-healing ulcers.

\section{References}

1. https://www.health.harvard.edu/diseases-and-conditions/footulcers

2. Alexiadou K, Doupis J (2012) Management of diabetic foot ulcers. Diabetes Therapy 3(1): 4 .

3. https://www.drugs.com/health-guide/foot-ulcers.html

4. Katsilambros N, Dounis E, Makrilakis K, Tentolouris N, Tsapogas $\mathrm{P}$ (2010) Atlas of the diabetic foot. ( $\left.2^{\text {nd }} e d n\right)$. Oxford: Wiley-Blackwell.
5. Prompers L, Huijberts M, Schaper N, Apelqvist J, Bakker K, et al. (2008) Resource utilisation and costs associated with the treatment of diabetic foot ulcers. Prospective data from the Eurodiale Study. Diabetologia 51(10): 1826-1834

6. Lala D, Spaulding SJ, Burke SM, Houghton PE (2016) Electrical stimulation therapy for the treatment of pressure ulcers in individuals with spinal cord injury: a systematic review and meta-analysis. Int Wound J 13(6): 1214-1226.

7. Turan Y, Ertugrul BM, Lipsky BA, Bayraktar K (2015) Does physical therapy and rehabilitation improve outcomes for diabetic foot ulcers? World J Exp Med 5(2): 130-139.

8. Rosenblum J, Gazes MI, Rosenblum S, Karpf A, Greenberg N (2017) A Multicenter Evaluation of Chronic Ulcer Recurrence with the Use of Varying Mechanical Wound Healing Modalities. J Vasc Med Surg 5(323): 2 .

9. Yim E, Kirsner RS, Gailey RS, Mandel DW, Chen SC, et al. (2015) Effect of physical therapy on wound healing and quality of life in patients with venous leg ulcers: a systematic review. JAMA dermatology 151(3): 320-327.

10. https://innovativemedicine.com/solutions/pulsed-electromagneticfield-therapy/

11. Yen-Patton GA, Patton WF, Beer DM, Jacobson BS (1988) Endothelial cell response to pulsed electromagnetic fields: stimulation of growth rate and angiogenesis in vitro. Journal of cellular physiology 134(1): $37-46$.

12. Avci P, Gupta GK, Clark J, Wikonkal N, Hamblin MR (2014) Low-level laser (light) therapy (LLLT) for treatment of hair loss. Lasers Surg Med 46(2): 144-151.

13. Karu T (1989) Photobiology of low-power laser effects. Health Physics 56(5): 691-704.

14. Litscher G, Wang L, Schikora D, Dagmar Rachbauer, Gerhard Schwarz, et al., (2004) Biological effects of painless laser needle acupuncture. Medical Acupuncture 16(1): 24-29.

15. https://www.marhythe-systems.de/en/

16. Abetz L, Sutton M, Brady L, McNulty P, Gagnon DD (2002) The Diabetic Foot Ulcer Scale (DFS): a quality of life instrument for use in clinical trials. Practical Diabetes International 19(6): 167-175.

17. Bann CM, Fehnel SE, Gagnon DD (2003) Development and validation of the Diabetic Foot Ulcer Scale-short form (DFS-SF). Pharmacoeconomics 21(17): 1277-1290.

18. http://www.medicalgnosis.com/topic/348-pressure-sores-andphysiotherapy-management/

19. Kwan RL, Wong WC, Yip SL, Chan KL, Zheng YP, et al. (2015) Pulsed electromagnetic field therapy promotes healing and microcirculation of chronic diabetic foot ulcers: a pilot study. Adv Skin Wound Care 28(5): 212-219.

20. Reddy AV, Prasad BC, Reddy GR, Maiya AG (2015) Effectiveness of Low Intensity Laser Therapy on The Wound Healing Using Bates Jensen Wound Assessment Tool in Subjects with Pressure Ulcers. International Journal of Physiotherapy 2(2): 416-420.

21. Taspinar F, Aslan UB, Sabir N, Cavlak U (2013) Implementation of matrix rhythm therapy and conventional massage in young females and comparison of their acute effects on circulation. J Altern Complement Med 19(10): 826-832.

22. https://www.marhythe-systems.de/en/die-therapie/

23. Sarı Z, Polat MG, Ozgul B, Aydogdu O, Camcioglu B, et al. (2014) The application of matrix rhythm therapy as a new clinical modality in burn physiotherapy programmes. Burns 40(5): 909-914. 
This work is licensed under Creative Commons Attribution 4.0 License DOI: 10.19080/JYP.2018.06.555696
Your next submission with Juniper Publishers will reach you the below assets

- Quality Editorial service

- Swift Peer Review

- Reprints availability

- E-prints Service

- Manuscript Podcast for convenient understanding

- Global attainment for your research

- Manuscript accessibility in different formats ( Pdf, E-pub, Full Text, Audio)

- Unceasing customer service

Track the below URL for one-step submission https://juniperpublishers.com/online-submission.php 